\title{
Novel compound heterozygous pathogenic variants in ASCC1 in a Chinese patient with spinal muscular atrophy with congenital bone fractures 2 : evidence supporting a "Definitive" gene-disease relationship
}

\section{Weiliang Lu}

Maternal and Child Health Hospital of Guangxi Zhuang Autonomous Region https://orcid.org/0000-0002-8671-8413

\section{Mingxing Liang}

Maternal and Child Health Hospital of Guangxi Zhuang Autonomous Regions

Jiasun Su

Maternal and Child Health Hospital of Guangxi Zhuang Autonomous Region

\section{Jin Wang}

Maternal and Child Health Hospital of guangxi Zhuang Autonomous Region

\section{Lingxiao Li}

Maternal and Child Health Hospital of Guangxi Zhuang Autonomous Region

\section{Shujie Zhang}

Maternal and Child Health Hospital of Guangxi Zhuang Autonomous Region

\section{Zailong Qin}

Maternal and Child Health Hospital of Guangxi Zhuang Autonomous Region

\section{Limei Huang}

Maternal and Child Health Hospital of Guangxi Zhuang Autonomous Region

Yingchi Lu

Maternal and Child Health Hospital of Guangxi Zhuang Autonomous Region

Shang Yi

Maternal and Child Health Hospital of Guangxi Zhuang Autonomous Region

Sheng Yi

Maternal and Child Health Hospital of Guangxi Zhuang Autonomous Region

\section{BoBo Xie}

Maternal and Child Health Hospital of Guangxi Zhuang Autonomous Region

Haiyang Zheng

Maternal and Child Health Hospital of Guangxi Zhuang Autonomous Region

\section{Jingsi Luo}

Maternal and Child Health Hospital of Guangxi Zhuang Autonomous Region

Xiaoyan Gao

Maternal and Child Health Hospital of Guangxi Zhuang Autonomous Region

Yiping Shen ( $\nabla$ yiping.shen@childrens.harvard.edu )

https://orcid.org/0000-0001-5820-0839

\section{Research}

Keywords: spinal muscular atrophy with congenital bone fractures 2, ASCC1, compound heterozygous, gene curation, exome sequencing

Posted Date: December 31st, 2019

DOI: https://doi.org/10.21203/rs.2.19730/v1

License: (c) (1) This work is licensed under a Creative Commons Attribution 4.0 International License. Read Full License 
Page 2/11 


\section{Abstract}

Background: A very limited spectrum of ASCC1 pathogenic variants had been reported in five (mostly consanguineous) families with spinal muscular atrophy with congenital bone fractures 2 [OMIM \#616867] since 2016.

Methods:A proband from a non-consanguineous Chinese family presented with neonatal severe hypotonia, respiratory distress, muscle weakness and atrophy, as well as congenital bone fractures was examined by exome sequencing.

Results: A compound heterozygosity of a nonsense (c.932C>G ,p.Ser311Ter) and an exon 5 deletion in ASCC1 segregating with phenotypes was detected, both variants are novel and pathogenic. Since ASCC1 is a relative new disease gene, we performed the gene curation following ClinGen SOP. The existing evidence is sufficient to support a "Definitive" level of disease-gene relationship.

Conclusion: This case report expended the mutation spectrum of ASCC1 and support the notion that this novel disease also occur in outbreed populations and this is a rare disease but may still be underdiagnosed due to its perinatal lethal outcomes.

Keywords: spinal muscular atrophy with congenital bone fractures 2; ASCC1; compound heterozygous; gene curation; exome sequencing

\section{Background}

ASCC1 encodes a subunit of the activating signal cointegrator 1 (ASC-1) complex. The ASC-1 complex is a transcriptional coactivator that plays an important role in gene transactivation by multiple transcription factors. Previous study showed that ASCC1 pathogenic variants were associated with Barrett esophagus and esophageal adenocarcinoma[1]. Recently, using WES, ASCC1 pathogenic variants were reported to cause bone fractures in neonates with lethal outcomes. Knierim et al identified a homozygous frameshift variant (c.157dupG, p.Glu53Glyfs*19) in ASCC1 in a patient with prenatal-onset spinal muscular atrophy (SMA), multiple congenital contractures (arthrogryposis multiplex congenita), respiratory distress, and congenital bone fractures[2]. The same variant at homozygous status were identified by Oliveira et al. in a patient with severe neonatal hypotonia, lack of spontaneous movements, microretrognathia and arthrogryposis, bilateral femoral fractures and thin, gracile ribs [3]. Three additional families were reported by Böhm et al. with prenatalonset muscle weakness with arthrogryposis and congenital bone fractures[4]. Two of the families were consanguineous and five affected individuals had the same homozygous variant. Only one family showed a compound heterozygous variant involving a nonsense variant (c.667C > T/p.Glu223*) and the recurrent frameshift variant. Thus, a total of ten patients from five independent families had been reported to be similarly affected. A total of three variants were uncovered so far and the recurrent frameshift variant occurred in six patients from three families. The narrow mutation spectrum of ASCC1 in patients mostly from consanguineous families limited our understanding of this severe condition. Here we report the first Chinese case and revealed two novel pathogenic variants, implicating the condition may be more widespread.

\section{Methods}

\section{Whole exome sequencing}

Genomic DNA was extracted from the peripheral blood samples. Target capture was done using an Agilent SureSelect Human All Exon kit (Agilent, Santa Clara, California, USA) according to the manufacturer's protocols, and sequencing was performed on an Illumina HiSeq2000 (Illumina). Sequence data were processed by GATK pipeline for SNV[5] and a custom pipeline for CNV detection combined with visual inspection of sequence read depth by IGV for possible exonic deletion. Variant filtering and prioritization were done using TGex (LifeMap Sciences, Alameda, CA). The variant pathogenicity was assessed according to ACMG/AMP guidelines[6].

\section{ASCC1 targeted variant analysis}

Sanger sequencing was carried out in the patient and in parental samples to confirm the nonsense variant identified by WES. The variant was described by the accession number NM_001198798.2 (ENST00000394919) for ASCC1. To confirm deletions involving exonic sequences, we designed one pair of MLPA probes for 3-8 exons. Since exon 5 is relatively large, we designed two pairs of probes for exon 5 (Table 1).

\section{Table 1}

The MLPA probe sequences 


\begin{tabular}{|c|c|c|c|c|c|}
\hline exon (Ex) & Target-speific hybridization sequences $\left(5^{\prime}-3^{\prime}\right)$ & $\mathrm{GC}(\%)$ & $\begin{array}{l}\operatorname{Tm} \\
\left({ }^{\circ} \mathrm{C}\right)\end{array}$ & $\begin{array}{l}\text { Target } \\
\text { sequence } \\
\text { length } \\
\text { (bp) }\end{array}$ & $\begin{array}{l}\text { Total } \\
\text { amplicom } \\
\text { size (bp) }\end{array}$ \\
\hline \multirow[t]{2}{*}{ ASCC1 EX3 } & C TCCATGGAGT GTGCTGATGA GCCCTGTGAT & 55 & 79.95 & 58 & 100 \\
\hline & GCCTACGAGG TGGAGCAGAC CCCACAA & 63 & 80.26 & & \\
\hline \multirow[t]{2}{*}{ ASCC1 EX4 } & GAGAGGGGAC ACTAGGAAGA AAATAGAAAT GGAGA & 43 & 74.26 & 78 & 120 \\
\hline & CCAAA АСTTCTATTAGCATTCCTAA ACCTGGACAAGACGGGGA & 44 & 80.08 & & \\
\hline \multirow[t]{2}{*}{ ASCC1 EX5a } & CACTGG CCAGCATCGA AATGGTGTAATTTCA & 45 & 76.41 & 64 & 108 \\
\hline & GCCCG AACACGGATT GATGTTCTTT TGGACACT & 48 & 79.21 & & \\
\hline \multirow[t]{2}{*}{ ASCC1 EX5b } & C CTCAATGAAG TTGAGGTTCAGGAAGGATTC CTGA & 46 & 78.03 & 70 & 112 \\
\hline & GATTCC AGGAGGAAGT ACTGGCGAAG TGCTCCATG & 54 & 81.22 & & \\
\hline \multirow[t]{2}{*}{ ASCC1 EX6 } & \multirow{2}{*}{$\begin{array}{l}\text { CATCTAACTA TTGGGATGTTGGTGCTTTTG AGTGAGGAAG } \\
\text { AGATCCAGCA GACATGTGAG ATGCTACAGCAGTG }\end{array}$} & 42 & 77.61 & 74 & 116 \\
\hline & & 50 & 77.10 & & \\
\hline \multirow[t]{2}{*}{ ASCC1 EX7 } & \multirow{2}{*}{$\begin{array}{l}\text { GATATTTC TGGGGGTAAA CCCCTAGAAGTGGAGATGGCAG GGATAGAA } \\
\text { TACATGAATG ATGATCCTGG CATGGTGGATGTTC }\end{array}$} & 50 & 80.92 & 82 & 124 \\
\hline & & 43 & 79.50 & & \\
\hline \multirow[t]{2}{*}{ ASCC1 EX8 } & \multirow{2}{*}{$\begin{array}{l}\text { GC TACAAGAATT AGTTGATCGAGTGCTGGAAC GTTTTCAGGC } \\
\text { ATCTGGACTA ATAGTGAAAG AGTGGAATAGTGTGAAACTGCATGC }\end{array}$} & 45 & 79.83 & 87 & 129 \\
\hline & & 40 & 76.86 & & \\
\hline
\end{tabular}

The MLPA was performed using the MLPA kit (P200-Reference-1-B1;MRC-Holland, Amsterdam, The Netherlands) according to the manufacturer's instructions.

\section{Results}

\section{Clinical description}

The proband was delivery at 37 weeks of gestation to a healthy mother (G2P2) from a non-consanguineous family (Fig. 1A). At 32 weeks of gestation, fetal ultrasound examination revealed an abnormal posture of upper limbs and club feet. The brain MRI indicated a mild bilateral lateral ventricle dilation with the left and right lateral ventricle posterior horn of approximately $1.26 \mathrm{~cm}$ and $1.12 \mathrm{~cm}$ in size, respectively (Fig. 1B). The delivery was uneventful with APGAR scores 5, 8, 8 at 1, 3 and 5 min, respectively. The neonate presented with pervasive edema, hypotonia, talipes equinovarus and humeral fractures (Fig. 1C-E). He had respiratory distress accompanied by pneumonia, coagulation abnormality and cryptorchidism. His ears were posteriorly rotated and low-set. He passed away at day 2 after birth. Detailed clinical data was shown in Table 2. 
Table 2

Clinical features of the patient reported in this work and comparison with published cases with ASC-1-related neuromuscular diseases

\begin{tabular}{|c|c|c|c|c|c|c|}
\hline & Family $1^{\text {Ref[8] }}$ & Family $2^{\text {Ref[9] }}$ & Family $3^{\text {Ref[10] }}$ & Family $4^{\operatorname{Ref}[10]}$ & Family $5^{\text {Ref[10] }}$ & This case \\
\hline $\begin{array}{l}\text { Number of } \\
\text { patients } \\
\text { (n) }\end{array}$ & 2 & 2 & 2 & 1 & 3 & 1 \\
\hline Country & Turkey & Portugal & Tunisia & Morocco & Sri Lanka & China \\
\hline Gender & Female & Male/Female & Male & Female & Male/Female & Male \\
\hline Locus & ASCC1 & ASCC1 & ASCC1 & ASCC1 & ASCC1 & ASCC1 \\
\hline $\begin{array}{l}\text { Pathogenic } \\
\text { variant }\end{array}$ & $\begin{array}{l}\text { c.157dupG } \\
\text { (p.Glu53Glyfs*19) } \\
\text { homo }\end{array}$ & $\begin{array}{l}\text { c.157dupG } \\
\text { (p.Glu53Glyfs*19) } \\
\text { homo }\end{array}$ & $\begin{array}{l}\text { c.157dupG } \\
\text { (p.Glu53fs19*) } \\
\text { homo }\end{array}$ & $\begin{array}{l}\text { c.157dupG } \\
\text { (p.Glu53fs19*) } \\
\text { c.466C>T } \\
\text { (p.Arg156*) } \\
\text { compound } \\
\text { heterozygous }\end{array}$ & $\begin{array}{l}\text { c. } 667 \mathrm{C}>\mathrm{T} \\
\left(\mathrm{p} . \mathrm{Glu} 223^{\star}\right) \\
\text { homo }\end{array}$ & $\begin{array}{l}\text { c. } 932 \mathrm{C}>\mathrm{G} \\
\text { (p.Ser311Ter); } \\
\text { Exon 5del } \\
\text { compound } \\
\text { heterozygous }\end{array}$ \\
\hline $\begin{array}{l}\text { Reduced/absent } \\
\text { fetal } \\
\text { movements }\end{array}$ & $\mathrm{Y}$ & $\mathrm{Y}$ & $\mathrm{U}$ & $U$ & $\mathrm{Y}$ & $\mathrm{Y}$ \\
\hline Poly/hydramnios & $\mathrm{Y}$ & $\mathrm{N}$ & $U$ & $U$ & $U$ & $\mathrm{~N}$ \\
\hline Oligohydramnios & $\mathrm{N}$ & $\mathrm{N}$ & $\mathrm{U}$ & $\mathrm{U}$ & $\mathrm{U}$ & $\mathrm{N}$ \\
\hline $\begin{array}{l}\text { Premature } \\
\text { delivery }(<37 \text { wk) }\end{array}$ & Y & $\mathrm{N}$ & $U$ & $\mathrm{~N}$ & $U$ & $\mathrm{~N}$ \\
\hline $\begin{array}{l}\text { Neonatal } \\
\text { hypotonia }\end{array}$ & $\mathrm{Y}$ & Y & $\mathrm{Y}$ & $\mathrm{Y}$ & $\mathrm{Y}$ & $\mathrm{Y}$ \\
\hline $\begin{array}{l}\text { Neonatal } \\
\text { respiratory } \\
\text { distress }\end{array}$ & $\mathrm{Y}$ & Y & $\mathrm{Y}$ & $\mathrm{Y}$ & $\mathrm{Y}$ & $\mathrm{Y}$ \\
\hline $\begin{array}{l}\text { Congenital bone } \\
\text { fractures }\end{array}$ & Y & $\mathrm{Y}$ & $Y$ & $Y$ & $\mathrm{Y}$ & $\mathrm{Y}$ \\
\hline $\begin{array}{l}\text { Joint } \\
\text { contractures }\end{array}$ & $\mathrm{Y}$ & Y & Y & Y & Y & $\mathrm{Y}$ \\
\hline $\begin{array}{l}\text { Muscle } \\
\text { weakness } \\
\text { and atrophy }\end{array}$ & $\mathrm{Y}$ & $\mathrm{Y}$ & $\mathrm{Y}$ & $\mathrm{Y}$ & $\mathrm{Y}$ & Y \\
\hline Cardiomyopathy & $\mathrm{N}$ & $\mathrm{N}$ & $\mathrm{N}$ & $\mathrm{N}$ & $\mathrm{N}$ & $\mathrm{N}$ \\
\hline Skin changes & $U$ & $\mathrm{~N}$ & $U$ & $U$ & $U$ & $\mathrm{Y}$ \\
\hline Brain imaging & $\begin{array}{l}\text { Abnormal cortical } \\
\text { gyration (MRI) }\end{array}$ & $\begin{array}{l}\text { N (transfontanel } \\
\text { ultrasonography) }\end{array}$ & NP & NP & $\mathrm{N}$ & $\begin{array}{l}\text { Y(lateral } \\
\text { ventricle } \\
\text { dilatation,mild })\end{array}$ \\
\hline $\begin{array}{l}\text { Skeletal muscle } \\
\text { histology }\end{array}$ & $\begin{array}{l}\text { Fiber size } \\
\text { variation } \\
\text { and atrophy. Type } \\
1 \text { fiber grouping }\end{array}$ & $\begin{array}{l}\text { Fiber atrophy } \\
\text { (limited analysis, } \\
\text { in the context of } \\
\text { autopsy) }\end{array}$ & $\begin{array}{l}\text { Fibre size } \\
\text { variability, } \\
\text { oxidative rims }\end{array}$ & $\begin{array}{l}\text { Fibre size } \\
\text { variability, } \\
\text { oxidative rims }\end{array}$ & $\begin{array}{l}\text { Fibre size } \\
\text { variability, } \\
\text { oxidative } \\
\text { rims, type I } \\
\text { fibre } \\
\text { predominance }\end{array}$ & NP \\
\hline Severity & $\begin{array}{l}\text { U(died } \\
\text { between } 2 \text { weeks } \\
\text { and } 16 \text { months of } \\
\text { life }\end{array}$ & $\begin{array}{l}\text { died within a few } \\
\text { days of life }\end{array}$ & $\begin{array}{l}\text { Deceased } \\
\text { shortly after } \\
\text { birth }\end{array}$ & $\begin{array}{l}\text { deceased at } \\
13 \text { days }\end{array}$ & $\begin{array}{l}\text { Deceased } \\
\text { shortly after } \\
\text { birth }\end{array}$ & $\begin{array}{l}\text { deceased at } 2 \\
\text { days }\end{array}$ \\
\hline
\end{tabular}

\section{Mutation analysis}


A heterozygous nonsense variant, c. $932 \mathrm{C}>\mathrm{G} / \mathrm{p}$.Ser311Ter in ASCC1 was detected in the proband and the father. It is predicted to lead to nonsense mediated decay. (Fig. 2A). We also detected an intragenic deletion involving exon 5 in the proband(Fig. 2B). The mother was the carrier of the deletion. (Fig. 2C). Both variants had not been previously reported. Both are null variants and are pathogenic according to the ACMG/AMP guidelines[6].

\section{Discussion}

ASCC1 (OMIM: 614215), contains 10 coding exons, and encodes a protein of the ASC-1 cointegrator complex that mediates the interaction of transcription factors with the basal transcription machinery to modulate gene expression[7]. More recently, ASCC1 was suggested to be a ribonucleoprotein complex involved in transcriptional coactivation of a wide range of genes and in RNA processing[2] and loss of function mutations were detected to be associated with a type of spinal muscular atrophy (MIM: 253300)[2]. Pathogenic variants in ASCC1 downregulated genes associated with neurogenesis, neuronal migration, and pathfinding, as well as with bone development[2]. So far, a total of ten patients from five independent families had been reported to be similarly affected by this perinatal lethal condition. Three variants including one highly recurrent frameshift variant (c.157dup (p.Glu53Glyfs*19) accounted for most of the pathogenic variants. Since this severe meuromuscular disorder caused by biallelic LOF variants in ASCC1 is a relative new disease-gene relationship and only a limited number of patient/pathogenic variants had been reported, we performed gene curation following the GlinGen gene curation protocol (https://clinicalgenome.org/site/assets/files/3907/gene-

disease_validity_standard_operating_procedures_version_7-1.pdf). Based on previously published cases and this Chinese family, the total clinical validity score reaches 14 (10 points from genetic evidence and 4 points from experimental evidence), thus sufficient evidence support a "Strong" gene-disease relationship. Now three years had passed since the first reported cases[2] and all affected individuals exhibited similar phenotypes and prognosis, overall, a "Definitive" level of disease-gene relationship can be concluded. We reported the second case with a compound heterozygous variant. In the previously reported ten cases, nonsense or frameshift variants are generally at the homozygous state and only one patient carried a compound heterozygous variant[4]. Our patient is the second case carrying a compound heterozygous variant in ASCC1.The report of the two affected individuals from this Chinese family extended the mutational spectrum and provided further evidence that this condition also occur in out populations.

Loss of function variants in ASCC1 are overall rare and never found to be homozygous in gnomAD (http://gnomad.broadinstitute.org/) except for the p.Ser78* nonsense variant which is located in an alternatively spliced exon and are believed to be not clinically relevant. There are 31 heterozygous LOF variants (Fig. 3) (should be at least likely pathogenic since both PVS1 and PM2 apply) and the overall pathogenic allele carrier rate is 0.0003 , thus the estimated disease incidence would be in the order of 9/40,000,000. Only 3 LOF variants were found in East Asian population, including two splice donor mutations and one frameshift mutation, the carrier AF was lower than 0.0001 , thus the disease incidence is expected to be lower in Asian. The mutation spectrum also different from population to population. Pathogenic variants from general population are found to be concentrated in exons 3,5 and 6 , and it is consistent with the distribution of pathogenic variants detected in patients (Fig. 2D), indicated that these 3 exons are more clinically relevant.

The clinical presentations of all reported patients are summarized in Table 2. This condition is mainly characterized by prenatal symptoms including decreased fetal movement, hydramnios, premature delivery, multiple fetal long bone fractures, arthrogryposis multiplex congenita and stiffness and neonatal sympotoms such as severe hypotonia, absence of deep tendon reflex, muscle weakness, muscle fiber abnormalities; abnormal cerebral cortical cerebral gyrus [2-4]. Our patient presented with hypotonia, congenital multiple deformity, neonatal respiratory distress, talipes equinovarus and humeral fractures, which are all major features of this condition. Interestingly, our patient also exhibited additional features not previously reported including cyanosis, ecchymoses, pneumonia, and cryptorchidism. In addition, his prothrombin time (PT), activated partial thromboplastin time (APTT) and thrombin time (TT) were significantly elevated ( 19.0 seconds, 76.3 seconds and 26.5 seconds, respectively), indicating coagulation abnormality. These novel features may added to our more complete understanding of this condition and can be used for differential diagnosis with other with spinal muscular atrophy related disorders.

\section{Conclusion}

We reported the first Chinese ASCC1 case with two novel pathogenic variants (the second compound heterozygous case). While the main clinical presentation of our patient is consistent with those of previously reported, novel phenotypes were also noticed. Although rare, this condition has poor prognosis and can be missed due to a neonatal lethal outcome. The current evidence support a definitive genedisease relationship. Additional cases are expected even in non-consanguineous populations. 


\section{Abbreviations}

ASCC1:activating signal cointegrator 1 complex subunit 1; LOF:Ioss of function; WES:Whole-exome sequencing; GATK:Genome Analysis Toolkit; SNV:single nucleotide variant; CNV:Copy number variant; IGV:Integrative Genomics Viewer; ACMG/AMP:The American College of Medical Genetics and Genomics/The Association for Molecular Pathology; PVS1:very strong pathogenic; PM2:moderate pathogenic; AF:Allele Frequency; MLPA:multiplex ligation-dependent probe amplification.

\section{Declarations}

\section{Acknowledgments}

The authors appreciate the participation of the patient and the parents for this study. We thank Maggie Huang for language editing.

\section{Authors'contributions}

WLL and MXL: study design, data analysis and manuscript writing. JW and ZLQ: study design and data analysis, LXL and JSL: collection of the clinical samples and clinical evaluation of the patients. JSS and SJZ: sequencing data analysis. SY and HYZ囚bioinformatics analysis. LMH and YCL: genomic DNA extraction. SY and BBX: MLPA anlysis. XYG and YPS: study design, data analysis, clinical evaluation of the patients and manuscript revision. All authors read and approved the final manuscript.

\section{Funding}

This work is partially supported by the "Eastern Scholar" Fund; the "Guangxi Bagui Scholar" fund; the Natural Science Foundation of China [Grant No.81873633]; National key research and development program (2018YFC1002501), the Major Research Plan of the Provincial Science and Technology Foundation of Guangxi (Grant No.AB16380214) and"YUMIAOJIHUA" Project of The Maternal \& Child Health Hospital of Guangxi Zhuang Autonomous Region (GXWCH-YMJH-2017005); the National Natural Science Foundation of China No. 81702919 and Guangxi Natural Science Foundation No. 2017JJB10161, the Guangxi Natural Science Foundation under Grant No. 2016 GXNSFBA380191.

\section{Availability of data and materials}

The datasets are available upon request.

\section{Ethics approval and consent to participate}

This work was approved by the ethics committee of Guangxi Maternal and Child Health Hospital. Written informed consent was obtained from the family.

\section{Consent for publication}

Consent for publication was obtained from all participants.

\section{Competing interests}

The authors declare no conflict of interest.

\section{Author details}

a Genetic and Metabolic Central Laboratory, Birth Defect Prevention Research Institute, Maternal and Child Health Hospital, Children's Hospital of Guangxi Zhuang Autonomous Region, Nanning, 530002 China.

${ }^{b}$ Department of Medical Genetics and Molecular Diagnostic Laboratory, Shanghai Children's Medical Center, Shanghai Jiao Tong University School of Medicine, Shanghai, 200127, China

${ }^{\mathrm{c}}$ Division of Genetics and Genomics, Boston Children's Hospital; Department of Neurology, Harvard Medical School, Boston, Massachusetts, 02115 USA. 
${ }^{d}$ Department of Neonatology, Maternal and Child Health Hospital of Guangxi Zhuang Autonomous Region, Nanning 530003, Guangxi, China.

\section{References}

1. Orloff M, Peterson C, He X, Ganapathi S, Heald B, et al. Germline mutations in MSR1, ASCC1, and CTHRC1 in patients with Barrett esophagus and esophageal adenocarcinoma.JAMA. 2011 Jul 27;306(4):410-9.

2. Knierim E, Hirata H, Wolf NI, Morales-Gonzalez S, Schottmann G,et al. Mutations in Subunits of the Activating Signal Cointegrator 1 Complex Are Associated with Prenatal Spinal Muscular Atrophy and Congenital Bone Fractures.Am J Hum Genet. 2016 Mar 3;98(3):473-489.

3. Oliveira J, Martins M, Pinto Leite R, Sousa M, Santos R,et al. The new neuromuscular disease related with defects in the ASC-1 complex: report of a second case confirms ASCC1 involvement.Clin Genet. 2017 Oct;92(4):434-439.

4. Böhm J, Malfatti E, Oates E, Jones K, Brochier G,et al. Novel ASCC1 mutations causing prenatal-onset muscle weakness with arthrogryposis and congenital bone fractures.J Med Genet. 2018 Oct 16.

5. McKenna A, Hanna M, Banks E, Sivachenko A, Cibulskis K,et al. The Genome Analysis Toolkit: a MapReduce framework for analyzing next-generation DNA sequencing data.Genome Res. 2010 Sep;20(9):1297-303.

6. Richards S, Aziz N, Bale S, Bick D, et al. Standards and guidelines for the interpretation of sequence variants: a joint consensus recommendation of the American College of Medical Genetics and Genomics and the Association for Molecular Pathology.Genet Med. 2015 May;17(5):405-24.

7. Jung DJ, Sung HS, Goo YW, Lee HM, et al. Novel transcription coactivator complex containing activating signal cointegrator 1 . Mol Cell Biol. 2002 Jul;22(14):5203-11.

\section{Figures}


A

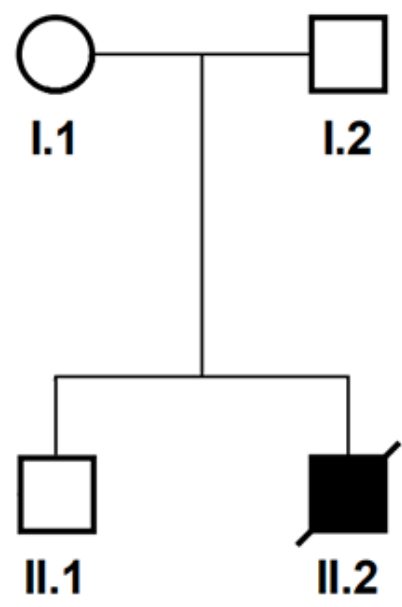

$\mathrm{D}$

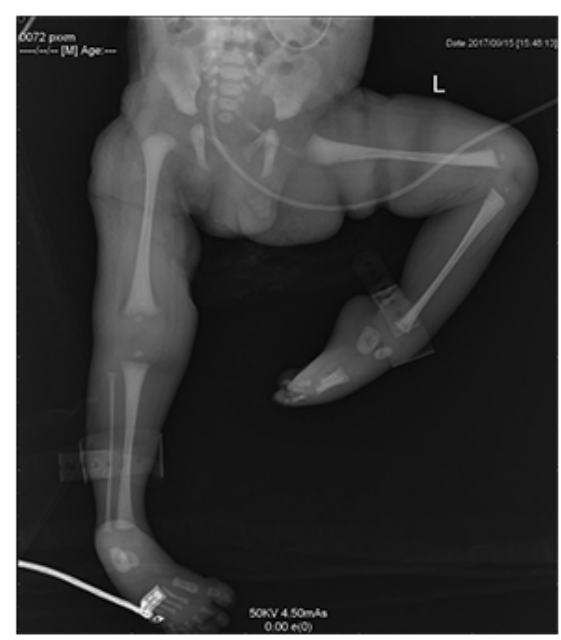

B

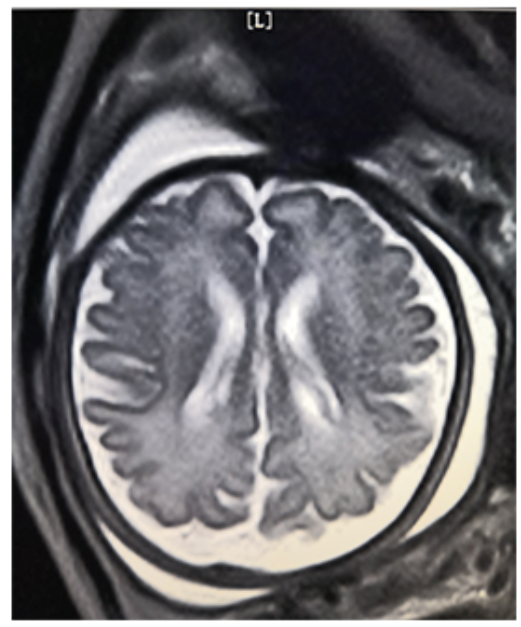

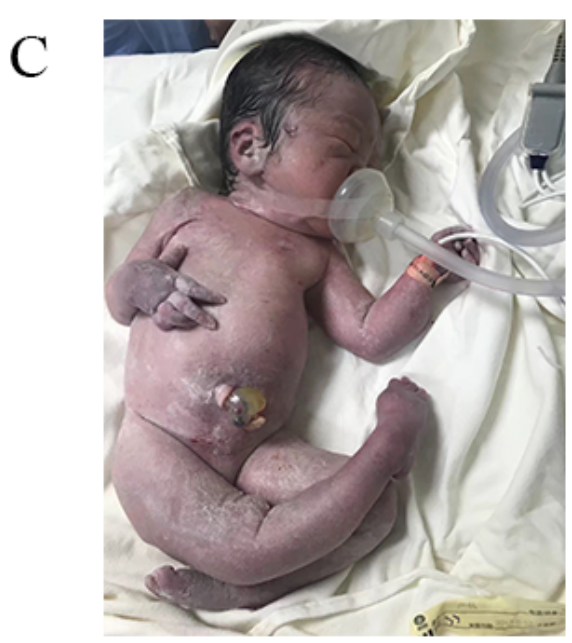

$\mathrm{E}$

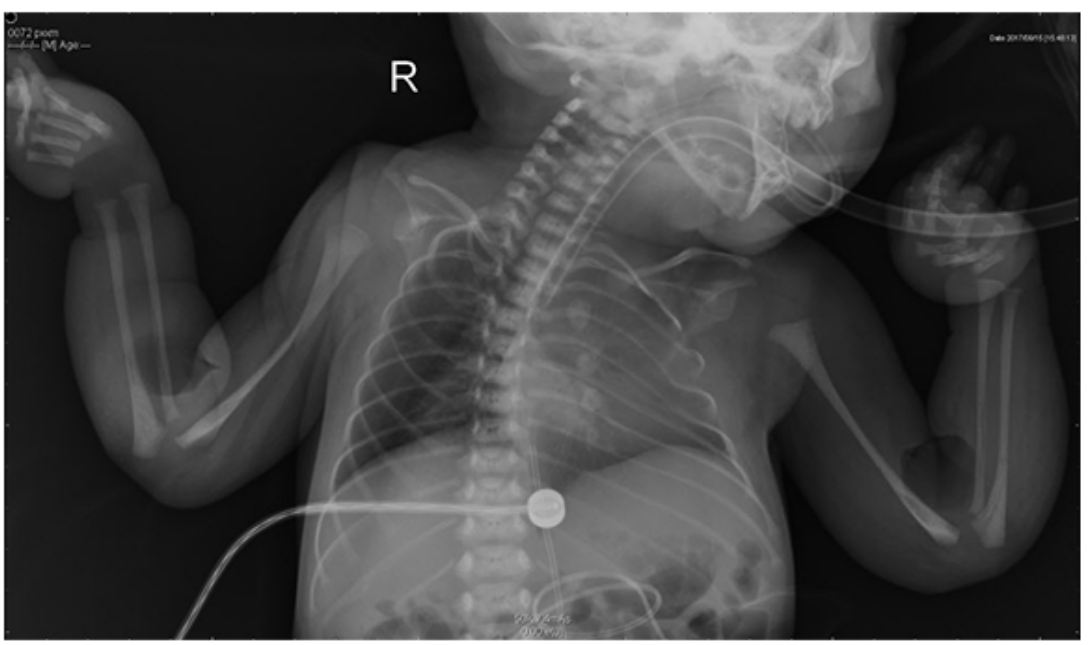

\section{Figure 1}

Family pedigree and patient's main clinical features. A: Pedigree of the family compatible with an autosomal recessive inheritance pattern. B: The MRI images of affected children II.2 (A). C: Myopathic appearance, including congenital multiple deformity, neonatal respiratory distress and talipes equinovarus. D-E: The malformation of lower limb and the bilateral congenital femoral fractures. 
A

Patient II.2

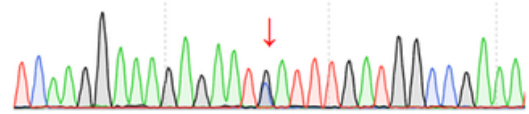

Father I.1

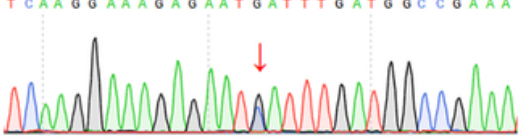

Mother I.2

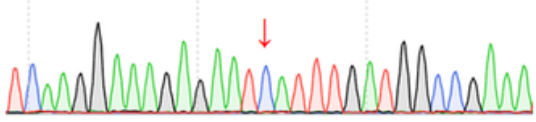

$\mathrm{C}$

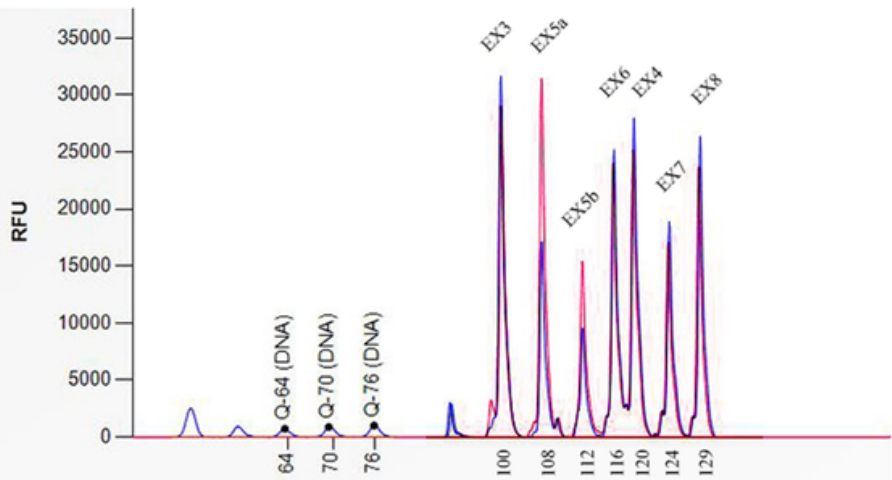

B

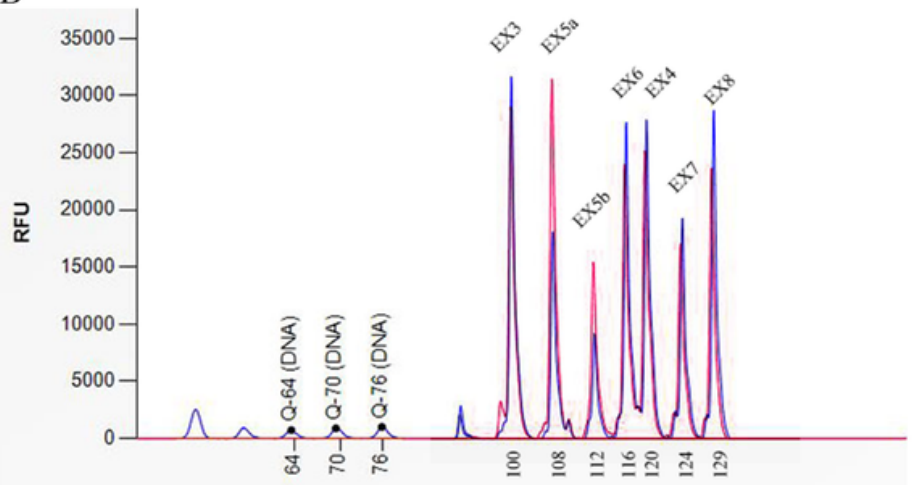

D

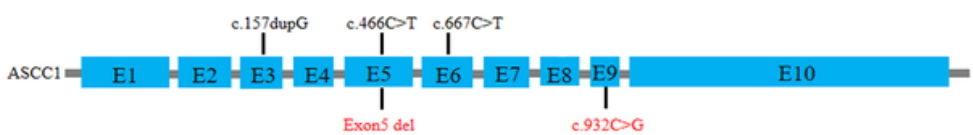

\section{Figure 2}

Identification of NM_001198799.2:C.932C>G and Exon 5 del variants in ASCC1 gene.A: Confirmation of variant by Sanger sequencing in the patient and in both parents.B: a deletion mutation in exon 5 was detected in the patient by using MLPA, and the mother was the carrier of this variant(C). The red peak represent the control that carried a complete ASCC1 gene, the blue peak represent the deletion of exon 5 in the proband and his mother; the X-axis represents the amplicoms of 3-8 exons by MLPA. D: Exon structure of the ASCC 1 gene and distribution of the mutations. The published mutations are depicted in black, the new ASCC1 mutations in our patient are highlighted in red. 


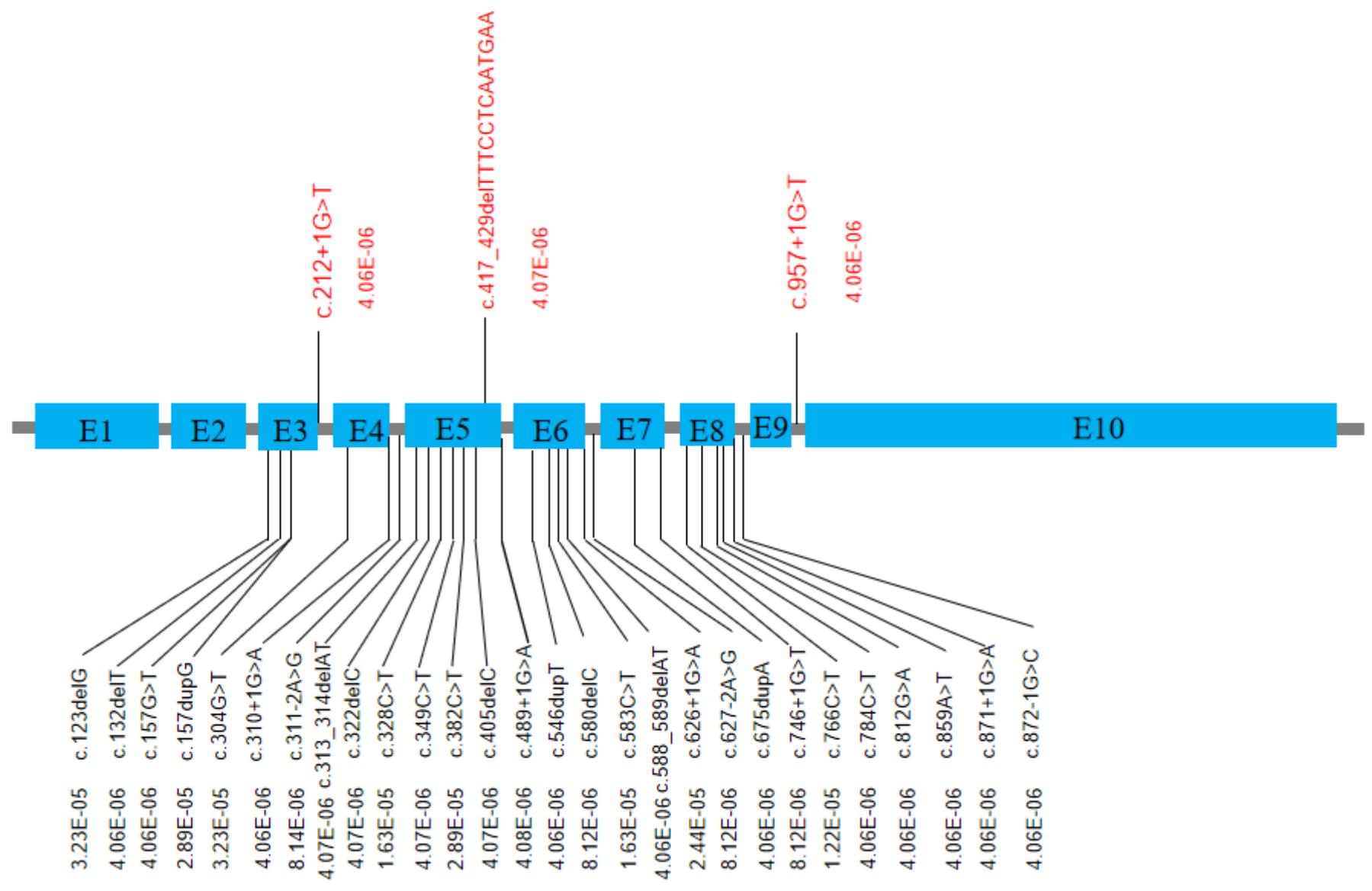

Figure 3

Schematic representation of exons and introns of ASCC1 with the heterozygous mutations identified in East Asian population(red) and in global population(black). 